\title{
Use of Microfiltered vs Only Disaggregated Mesenchymal Stem Cells from Adipose Tissue in Regenerative Medicine
}

\author{
Fabiano Svolacchia, ${ }^{1}$ Lorenzo Svolacchia ${ }^{2}$
}

\begin{abstract}
Background: Clinical use of adult mesenchymal stem cells (MSCa) in medicine and regenerative surgery is constantly evolving. Adipose tissue-derived stem cells (ADSc) are capable of inducing the production of new extracellular matrix (ECM), deposition of new collagen and early revascularisation.

Methods: Flow cytometry was performed for $2 \mathrm{~mL}$ of cell colonies harvested from adipose tissue (AT). Comparation has been made of AT disaggregated only and the same AT disaggregated and microfiltered at $50 \mu \mathrm{m}, 100 \mu \mathrm{m}$ and $200 \mu \mathrm{m}$. Signs of inflammation after dermo-epidermal regeneration session through the mesotherapy method were observed and compared.

Results: Even after filtration, significant number of ADSc was collected. An increase in the size of the filter did not always translate into an increase in the number of cells that were found in the microfiltrate. In the non-filtered AT disaggregated in both cases, highest number of cells was found, as expected, but at the expense of more pronounced inflammation. Sampling with the 16 Gauge needle produces superior results compared to the cannula in all cases.

Conclusion: With this method in medicine and regenerative surgery it will be easier to exploit the growth factors, mRNA, MicroRNA, lipids and bioactive peptides emitted in the MSCa signalling micro-vesicles as they are isolated from the inflammatory component.
\end{abstract}

Key words: Mesenchymal stem cells; Adipose tissue-derived stem cells, Side-population cells; Filtration; Flow cytometry.
(1) Department of Anatomical, Histological, Medical and Legal Sciences and the Locomotor Equipment, Section of Human Anatomy, Laboratory of Experimental Morphology at the University of Rome "La Sapienza", Rome, Italy.

(2) Faculty of Medicine and Surgery, University of Rome "La Sapienza", Rome, Italy.

Correspondence:

FABIANO SVOLACCHIA

E: fabiano.svolacchia@gmail.com

\section{ARTICLE INFO}

Received: 26 January 2020

Revision received: 23 August 2020 Accepted: 24 August 2020

\section{Introduction}

Tissue progenitors with adult stem markers present in the mesenchyme and used in medicine as regenerative therapy induce their clinical response by means of a complex and dynamic interaction between the cells, growth factors and blood vessels present in the extracellular matrix (ECM). ${ }^{1}$ Adult progenitors are those that can be isolated in an autologous tissue sample of mes- enchymal origin and that best embed cells with characteristics of adult stem cell on cytometric examination. They are contained in the so-called side population (SP) and are also referred to as MSCa. The MSCa derived from adipose tissue (AT) or adipose tissue-derived stem cells (ADSc) and their secretion micro-vesicles are capable of inducing the production of new ECM, deposi- 
tion of new collagen and early revascularisation not influenced by hypoxia. ${ }^{2}$ Clinical success of a therapy carried out through a microfiltered AT disaggregated at predetermined measures of 50 and 100 micrometres $(\mu \mathrm{m})$ in order to safeguard the tissue progenitors has been demonstrated both in chrono-ageing and in photo-ageing., ${ }^{3,4}$ After publishing the clinical success of a technique that included the exclusion of fibrous branches and cellular debris because they are potentially inflammatory.$^{5-7}$ By preserving the SP, the proregenerative properties related to the transmission of extracellular vesicles are preserved, which contain the different types of molecules including RNA, ranging in size from 30 to $100 \mathrm{~nm}$, nucleic acids (DNA, mRNA and microRNA), signalling proteins and lipids for target cells..$^{8,9}$ If excluding the inflammatory phase, it is possible to epigenetically reprogramme the receiving cells by altering their phenotype and activating an inversion of fibrosis. ${ }^{10}$ This information is transferred through an intercellular communication of the signalling micro-vesicles that will induce the resolution of fibrosis, the inhibition of the activation of macrophages, the inhibition of the secretion of inflammatory cytokines and the remodelling of the ECM with reduction of scar tissue. ${ }^{10}$ Through the micro-vesicles emitted by ADSc deprived of the inflammatory component, the functional phenotype of the mother cell as a therapeutic will be maintained. ${ }^{11}$

\section{Methods}

The quantities of viable cells contained in $2 \mathrm{~mL}$ of AT according to Tonnard et $\mathrm{al}^{12}$ were microfiltered at various sizes and without any microfiltration by cytometric examination..$^{13}$ The samples were taken from the same patient, in the same operating session and in the same anatomical site of the abdomen both with a 16 Gauge (16G) needle and with a small hole multiport cannula, after carrying out a tumescent anaesthesia in order to preserve the vitality of the MSCa contained in the adult tissue compared to a simple local anaesthesia. ${ }^{14}$ The patient signed an informed consent for the use of lipoaspirate for experimental procedures. The study was performed following the standards of the local ethics committee and in accordance with the Helsinki Declaration (2000).
After collection and disaggregation, all AT samples were cultured ( 1 flask T75 / sample) in the presence of $10 \mathrm{~mL}$ of ALFA-MEM medium with $10 \%$ foetal bovine serum and antibiotic. After two days, cells were present in all the flasks. In the following two days the flasks of samples A, B and $\mathrm{D}$, those containing the $16 \mathrm{G}$ needle collection, were confluent and the cells were then detached and the flow cytometric analysis of specific mesenchymal (CD29, CD44, CD73, CD105) and hematopoietic (CD45) markers was performed. After two more days the flasks containing the samples C, E, F and G, those extracted with the small hole multiport cannula, had also reached confluence and flow cytometric analysis of specific mesenchymal markers was carried out. All the samples were analysed for mesenchymal markers.

Signs of inflammation after dermo-epidermal regeneration session through the mesotherapy method with $1 \mathrm{~mL}$ syringe and Luer attachment and 30G $6 \mathrm{~mm}$ needle with the non-microfiltered disaggregated ADSc were observed and compared to the same treatment with disaggregated microfiltered ADSc at $50 \mu \mathrm{m}$.

\section{Results}

Two days after collection, disaggregation and cultivation of cells were present in all the flasks. The richest cell sample was $D$, the poorest $C$, while samples A and B were equivalent. Sample G was richer in $\mathrm{E}$ and $\mathrm{F}$.

In samples collected with $16 \mathrm{G}$ needle (A, B and D) the following were recovered: in sample A (filtration at $50 \mu \mathrm{m}$ ): 1,350,000 cells; in sample B (filtration at $100 \mu \mathrm{m}$ ): 1,170,000 cells; in sample D (no filtration): 1,870,000 cells (Figure 1 ).

In samples extracted with small hole multiport cannula $(\mathrm{C}, \mathrm{E}, \mathrm{F}, \mathrm{G})$ the following were recovered: 980,000 cells were recovered in sample C (filtration at $200 \mu \mathrm{m}$ ); in sample $\mathrm{E}$ (filtration at 50 $\mu \mathrm{m}): 1,125,000$ cells; in sample F (filtration at 100 $\mu \mathrm{m}): 1,364,000$ cells; in sample $\mathrm{G}$ (no filtration): 1,560,000 cells (Figure 2).

All the samples analysed were positive for all 
Sample A
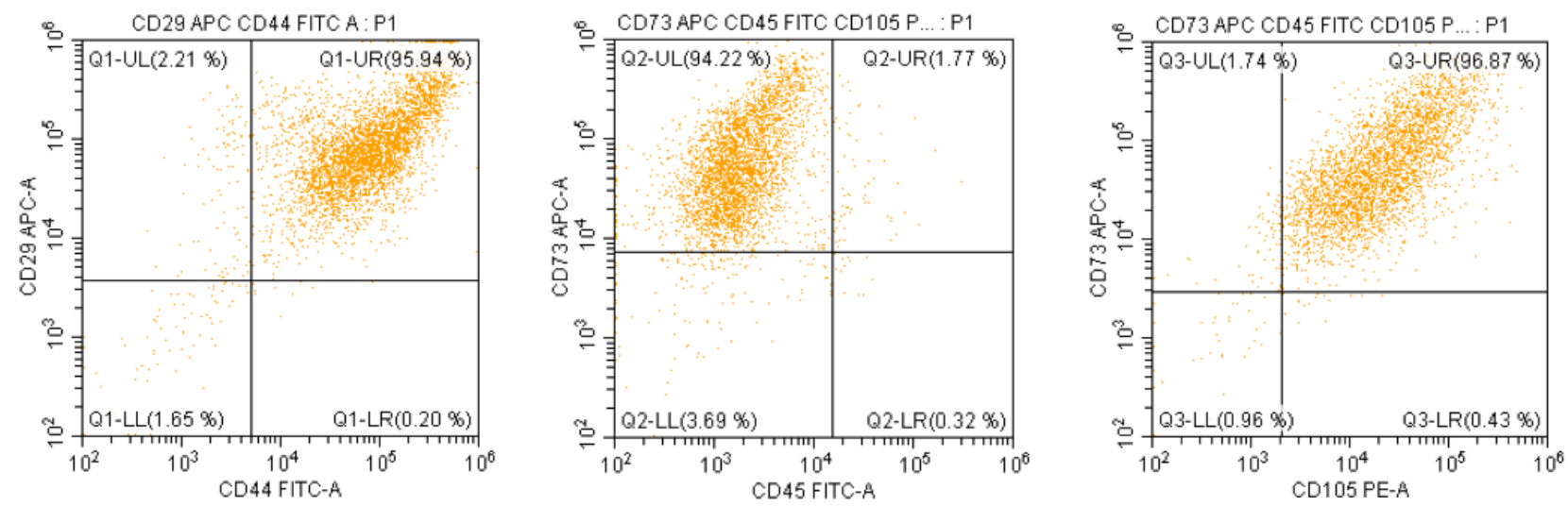

Sample B
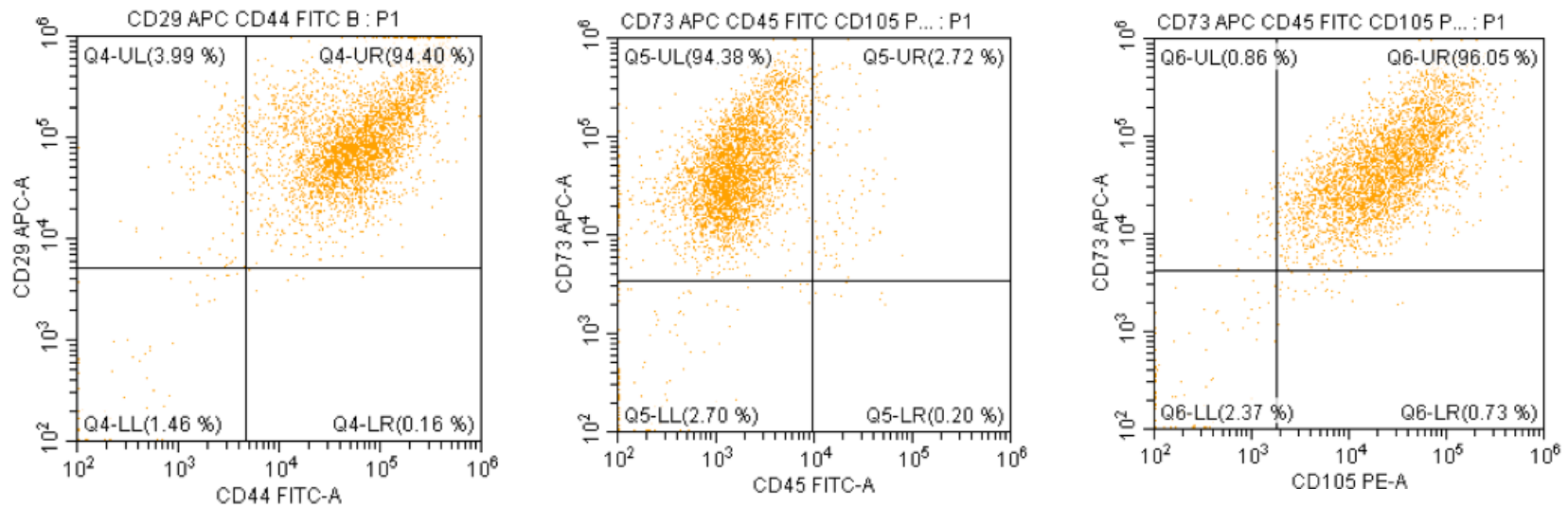

Sample $D$
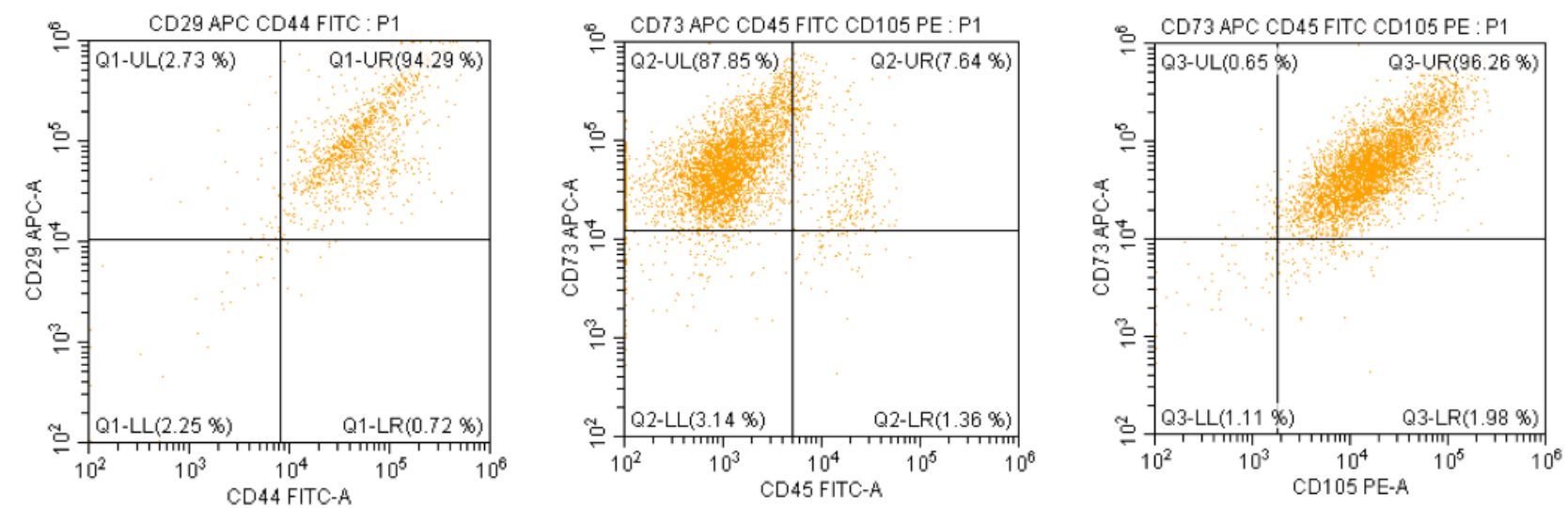

Figure 1: Flow cytometry of adipose tissue derived stem cells (ADSC) samples collected with $16 \mathrm{G}$ needle.

Sample A) with filtration at $50 \mu \mathrm{m}(1,350,000$ cells); Sample B) with filtration at $100 \mu \mathrm{m}$ (1,170,000 cells); Sample D) no filtration (1,870,000 cells)

mesenchymal markers. The population of CD45 + cells (hematopoietic cell contamination) was minimal.

When comparing signs of inflammation (rubor, dolor, calor), temporary increase of the signs was noticed about 30 minutes after treatment. Clini- cally observed, signs of inflammation were more expressed with treatment with $1 \mathrm{~mL}$ syringe and Luer attachment and 30G $6 \mathrm{~mm}$ needle with the non-microfiltered disaggregated (Figure 3) compared to the same treatment with disaggregated microfiltered ADSc at $50 \mu \mathrm{m}$ (Figure 4). 
Sample $E$
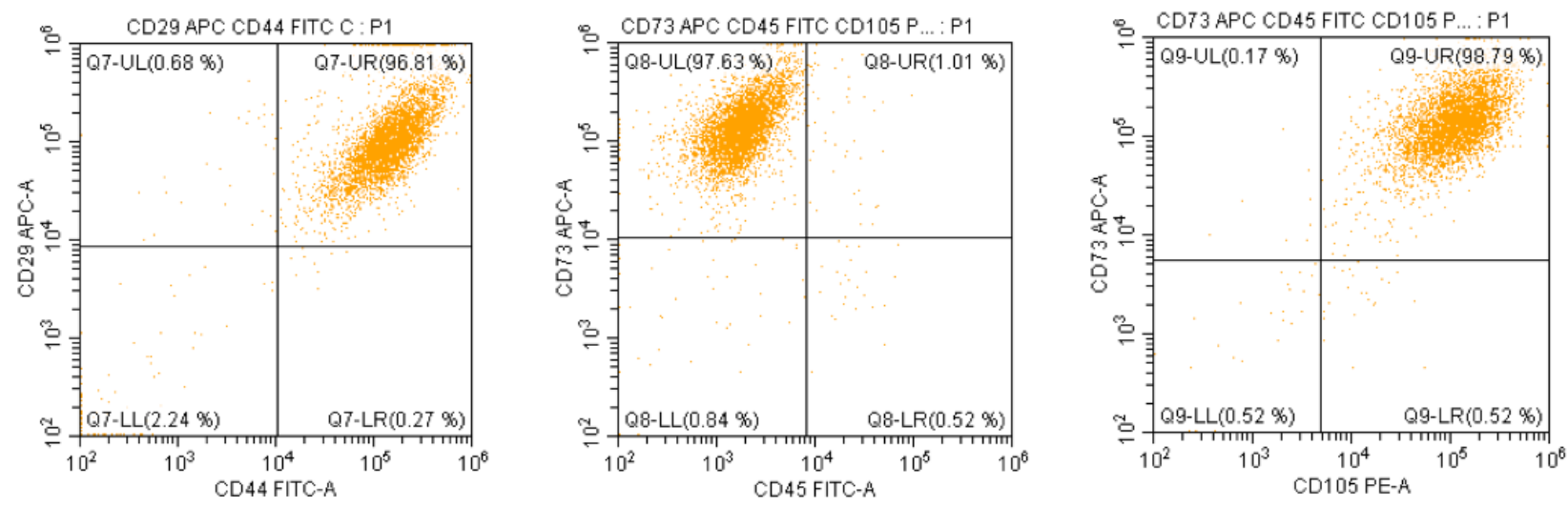

Sample F
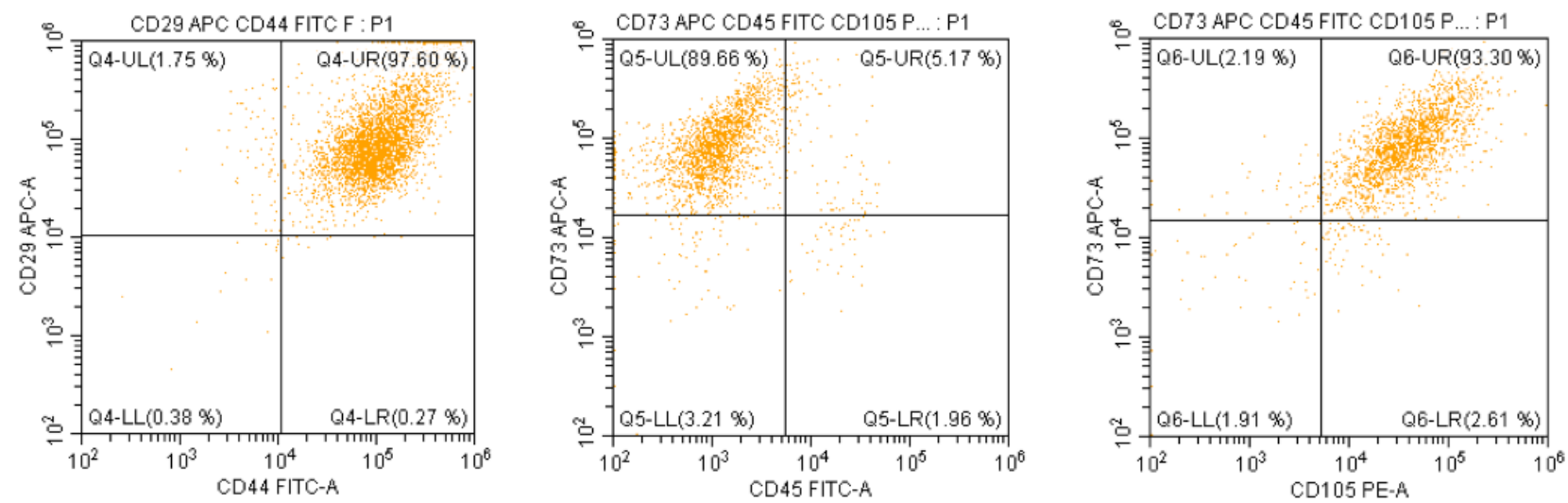

Sample C
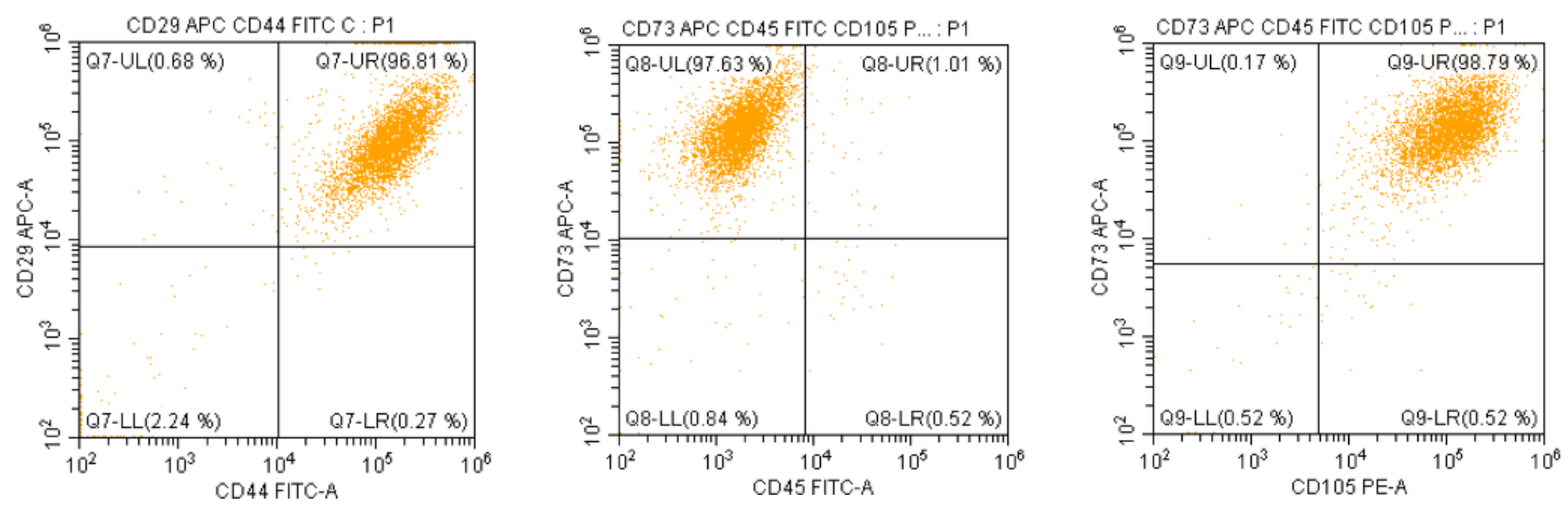

Sample G
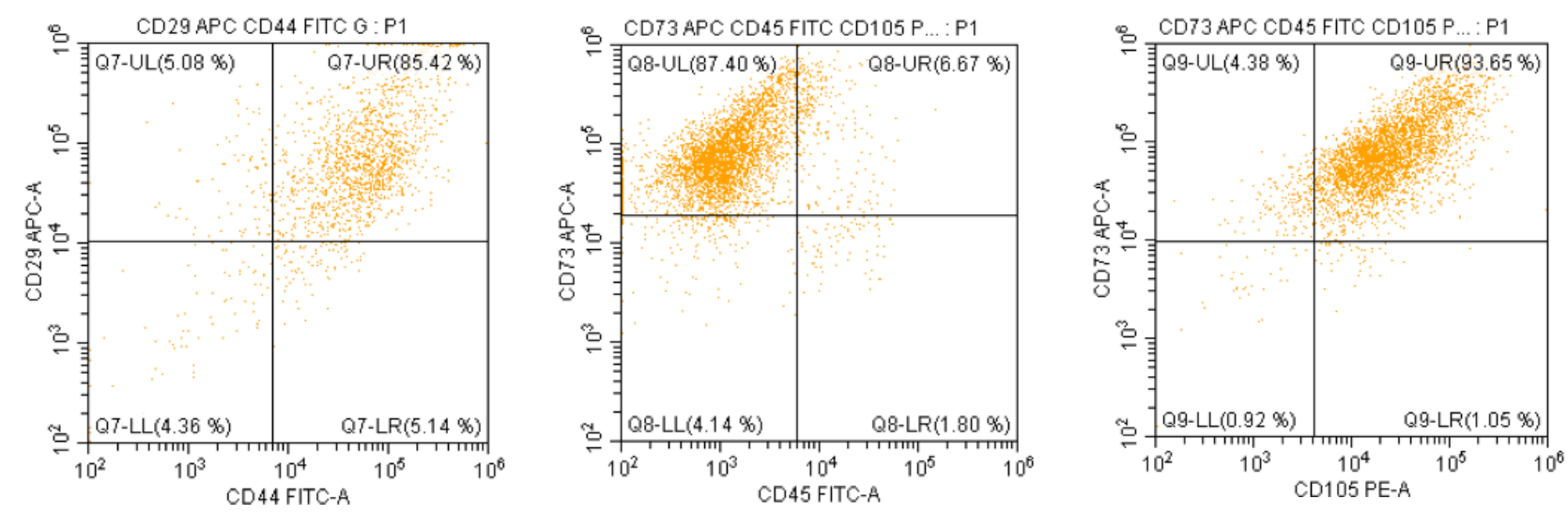

Figure 2: Flow cytometry of adipose tissue derived stem cells (ADSc) samples collected with lipoaspiration cannula.

Sample E) with filtration at $50 \mu \mathrm{m}$ (1,125 cells); Sample F) with filtration at $100 \mu \mathrm{m}$ (1,364,000 cells); Sample C) with filtration at $200 \mu \mathrm{m}(980,000$ cells); Sample G) no filtration (1,560,000 cells); 


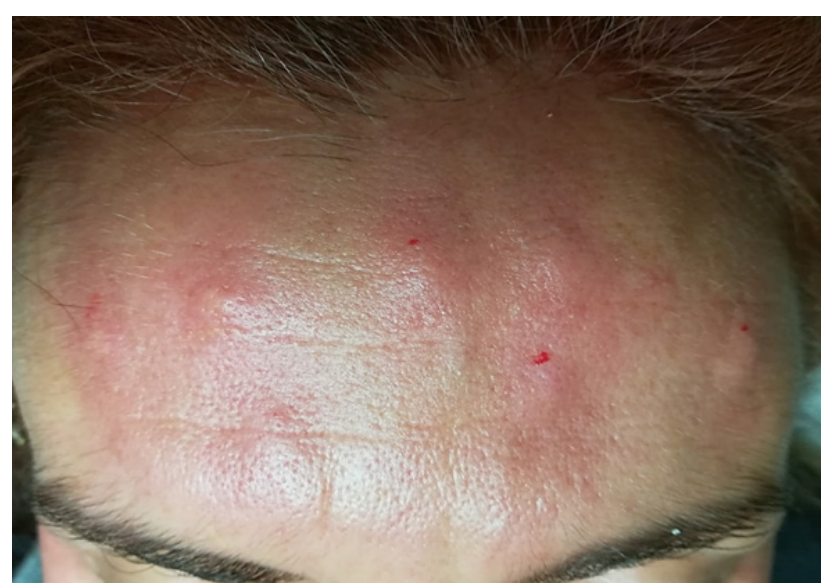

Figure 3: Signs of inflammation after treatment with $1 \mathrm{~mL}$ syringe and Luer attachment and 30G $6 \mathrm{~mm}$ needle with the non-microfiltered disaggregated adipose tissue derived stem cells (ADSc).

\section{Discussion}

In this study it is compared some of the possible methods that allow us to use a small sample of AT for tissue regeneration. The comparison was made between sampling with a small hole multiport cannula versus a 16G needle and between a fat disaggregated according to Tonnard et $\mathrm{al}^{12}$ and its filtrations at 50, 100 and $200 \mu \mathrm{m}$.

Collecting MSCa from AT is convenient, as it is easily available, repeatable and AT is non-essential. Also, ASCs have been shown to have higher proliferation capacities than bone marrow MSC. ${ }^{15,16}$ Differences in the proliferation time of ASCs originating from different regions of the body have been reported..$^{17-19}$

Sampling with a $16 \mathrm{G}$ needle was richer in progenitors with adult stem cell outlines, those that best embody MSCa, compared to drawing with the cannula. Filtration maintained an excellent quantity of cells with stem markers allowing the elimination of fibrous branches and cellular debris potentially inflammatory in both extraction methods. The filtration of the sampling with a needle at $50 \mu \mathrm{m}$ contrary to what could be expected gave a higher result than the filtration at $100 \mu \mathrm{m}$. The exact opposite occurred with the disaggregated and microfiltered AT from the collection with the cannula. Of this latter sampling, the filtration at $200 \mu \mathrm{m}$ produced a numerically

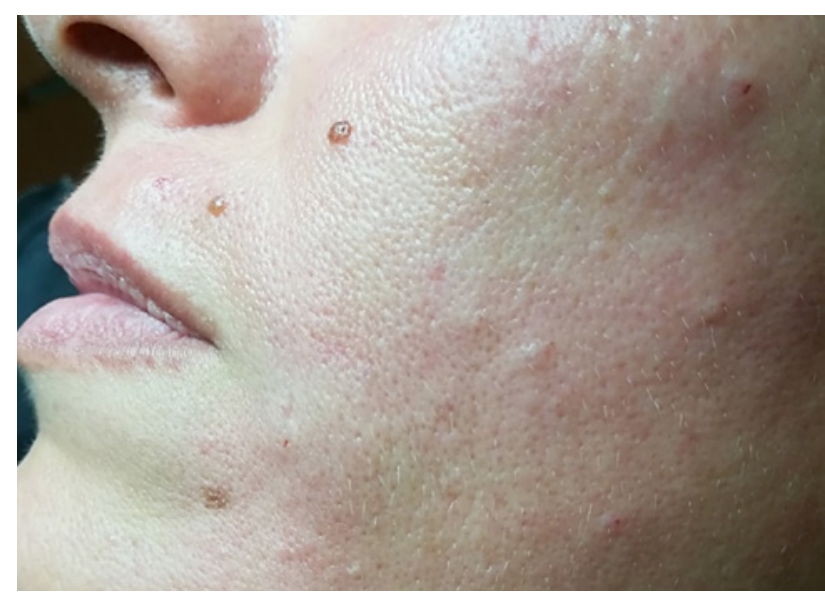

Figure 4: Signs of inflammation after treatment with $1 \mathrm{~mL}$ syringe and Luer attachment and 30G $6 \mathrm{~mm}$ needle with the microfiltered disaggregated adipose tissue derived stem cells (ADSC) at $50 \mu \mathrm{m}$.

lower presence in cells but still very high, due to the small amount of AT used (2 mL).

In the non-filtered AT disaggregated in both cases, the greatest presence of cells was found, as expected, but at the expense of more pronounced inflammation. There were changes at the injection point on the dermis during the mesotherapy treatment between a microfiltrate and the AT disaggregated according to Tonnard et al. ${ }^{12}$ During the procedure without filtration some of the clinical signs of inflammation that spontaneously regressed after about 30 minutes were observed. Those were practically absent in the mesotherapy treatment with the microfiltrate. Not only that, although there is a loss of cells during the disaggregation carried out according to Tonnard et $\mathrm{al}^{12}$ and subsequent filtration, their vital and replication potential after the selection of the AT by filtration turns out to be higher than the simple disaggregation. ${ }^{20,21}$ Through the cytometry studies reported in this study, it was clear that the microfiltration technique is suitable for preserving the SP and with it the MSCa for each regeneration treatment by mesotherapy therapy supplementation of tissue progenitors, resulting clinically preferable to the unfiltered unbundled. In this study it is shown that during filtration there is a loss in the number of cells with adult stem cell markers that are stuck in the mesh- 
es of fibrous branches and cellular debris. It is also shown that an increase in the size of the filter does not always translate into an increase in the number of cells that are found in the microfiltrate. Very high number of viable cells can be found even in a microfiltrate from only $2 \mathrm{~mL}$ of
AT. That translate clinically into a better success since it lacks the inflammatory component. Data has shown that sampling with the 16G needle produces superior results compared to the cannula in all cases.

\section{Conclusion}

The filtering technique is simple, fast, reproducible and economic, it allows for to have a very high suspension of cells, is more efficient in terms of vital potential and replication for all medical and surgical regenerative techniques compared to the simple disaggregated according to Tonnard et al. ${ }^{12}$ Its use can also be defined as safe and preferable based on the authors' clinical experience.

\section{References}

1. Patricia A, Zuk PA, Zhu M, Ashjian P, De Ugarte DA, Huang JI, et al. Human adipose tissue is a source of multipotent stem cells. Mol Biol Cell 2002 Dec;13(12):4279-95.

2. Hass R, Kasper C, Böhm S, Jacobs R. Different populations and sources of human mesenchymal stem cells (MSC): A comparison of adult and neonatal tissue-derived MSC. Cell Commun Signal. 2011 May 14;9:12. doi: 10.1186/1478-811X-9-12.

3. Svolacchia F, Svolacchia L. Autologus micrograft fat injection: microfiltration technique of disaggregated adipose tissue and skin regeneration. A clinical assessment study. J Plast Dermatol Pathol 2019;15(1):31-7.

4. Svolacchia F, Svolacchia L. Dermal regeneration with MilliGraft $\AA$ kit of nanofat: the micrograft of adipose tissue. A clinical assessment study. Scr Med 2019;50(3):117-21.

5. Janis JE, Harrison B. Wound healing: part I. Basic science. Plast Reconstr Surg 2014 Feb;133(2):199e-207e.

6. Sezgin B, Ozmen S, Bulam H, Omeroglu S, Yuksel S, Cayci B, Peker T. Improving fat graft survival through preconditioning of the recipient site with microneedling. J Plast Reconstr Aesthet Surg 2014 May;67(5):712-20.

7. Pontieri GM, Russo MA, Frati L, editors. [General pathology]. 4th edition. Padua: Piccin Editore, 2011. p. 399445. Italian.

8. Capomaccio S, Cappelli K, Bazzucchi C, Coletti M, Gialletti R, Moriconi F, et al. Equine adipose-derived mesenchymal stromal cells release extracellular vesicles enclosing different subsets of small RNAs. Stem Cells Int 2019 Mar 18;2019:4957806. doi: 10.1155/2019/4957806. eCollection 2019.

9. Jan AT, Rahman S, Khan S, Tasduq SA, Choi I. Biology, Pathophysiological role, and clinical implications of exosomes: a critical appraisal cells 2019 Jan 29;8(2). pii: E99. doi: 10.3390/cells8020099.

10. Chen YW, Scutaru TT, Ghetu N, Carasevici E, Lupascu CD, Ferariu D, et al. The effects of adipose-derived stem cell-differentiated adipocytes on skin burn wound healing in rats. J Burn Care Res 2017 Jan/Feb;38(1):1-10.

11. Liu A, Zhang X, He H, Zhou L, Naito Y, Sugita S, Lee JW. Therapeutic potential of mesenchymal stem/stromal

\section{Acknowledgements}

None.

\section{Conflict of interest}

None. cell derived secretome and vesicles for lung injury and disease. Expert Opin Biol Ther 2020 Feb;20(2):125-40.

12. Tonnard P, Verpaele A, Peeters G, Hamdi M, Cornelissen $M$, Declercq $H$. Nanofat grafting: basic research and clinical applications. Plast Reconstr Surg 2013 Oct;132(4):1017-26.

13. Fulwyler MJ. Electronic separation of biological cells by volume. Science 1965 Nov 12;150(3698):910-1.

14. Wang WZ, Fang XH, Williams SJ, Stephenson LL, Baynosa RC, Khiabani KT, Zamboni WA. Lidocaine-induced ASC apoptosis (tumescent vs. local anesthesia). Aesthetic Plast Surg 2014 Oct;38(5):1017-23.

15. Kern S, Eichler H, Stoeve J, Kluter H, Bieback K. Comparative analysis of mesenchymal stem cells from bone marrow, umbilical cord blood, or adipose tissue. Stem Cells 2006;24:1294-1301.

16. Schäffler A, Büchler C. Concise Review: adipose tissue-derived stromal cells-basic and clinical implications for novel cell-based therapies. Stem Cells 2007 Apr;25(4):818-27.

17. Shi YY, Nacamuli RP, Salim A, Longaker MT. The osteogenic potential of adipose-derived mesenchymal cells is maintained with aging. Plast Reconstr Surg 2005;116:1686-96.

18. Schipper BM, Marra KG, Zhang W, Donnenberg AD, Rubin JP. Regional anatomic and age effects on cell function of human adipose-derived stem cells. Ann Plast Surg 2008;60:538-44

19. Van Harmelen V, Rohrig K, Hauner H. Comparison of proliferation and differentiation capacity of human adipocyte precursor cells from the omental and subcutaneous adipose tissue depot of obese subjects. Metabolism 2004:53:632-7.

20. Bi HS, Zhang C, Nie FF, Pan BL, Xiao E. Basic and clinical evidence of an alternative method to produce vivo nanofat. Chin Med J (Engl) 2018 Mar 5;131(5):588-93.

21. Fraser JK, Wulur I, Alfonso Z, Hedrick MH. Fat tissue: an underappreciated source of stem cells for biotechnology. Trends Biotechnol 2006;24:150-4. 